\title{
The Quantification of Polyphenolic Potential of the Black Grapes for Winemaking
}

\author{
Laura FOTESCU ${ }^{1 *}$, Aurelia TUDORACHE ${ }^{1}$, Elena BRINDUSE ${ }^{1}$, Liliana PIRCALABU ${ }^{1}$ \\ ${ }^{1}$ Research and Development Institute for Viticulture and Enology Valea Calugareasca, Valea Mantei \\ Street, no.1, Valea Calugareasca, zipe code 107620, Prahova, Romania, \\ *)corresponding author, e-mail: laurafotescu@yahoo.com
}

BulletinUASVM Horticulture 72(2) / 2015

Print ISSN 1843-5254, Electronic ISSN 1843-5394

DOI:10.15835/buasvmcn-hort:10722

\begin{abstract}
The polyphenolic potential of the harvest is defined by: polyphenol index, total anthocyanincontent, extractable anthocyanins and seed maturity. The reserches was conducted during 2012 - 2013 period, in the Appelation of Controlled Origin, Dealu Mare -Valea Călugărească area and had the following objectives: characterization of climate and the maturation of grapes function of the harvest year and determination of the qualitative level of varieties based on parameters of phenolic maturity. The average air temperature registered during the ripening of the grapes was higher with $2,6^{\circ} \mathrm{C}$ in 2012 in comparison with the same period in 2013 . The veraison was recorded earlier with 3 days in 2013 and the harvesting later with 7 days compared to 2012 harvest. The kinetics of grapes maturation was very slow in 2013 and rapid in 2012. The phenolic maturity of grapes at harvesting was very good for most of the features in 2012 and mediocre in 2013.
\end{abstract}

Keywords: black grapes, phenolic maturity, veraison

\section{INTRODUCTION}

The knowledge regarding "the phenolic identity" of the raw material is very important to establish the strategies for the black grapes winemaking (Vivas et al., 1998).

The phenolic maturity is a characteristic of the black grapes for winemaking and a component of the qualitative potential of the harvest. It gaves informations regarding the grapes content in phenols and anthocianins, the anthocianins extractability and the share of astringent tannins ().

The phenolic maturity of the grapes is direct related with the viticultural climate. It shows a great variability but can be evaluated on a qualitative level on a scale from 1 to 5 as follows: 1. exceptional, 2 . very good, 3 . good, 4 . medium and 5. mediocre. The values of the parameters associated to each qualitative level are specific to the variety and the viticultural area and is defined based on scientific studies.
The precocity of veraison represents the vine response to its natural environment and is decisive for the quality of the phenolic potential of grapes. It is evaluated by comparison with the average multiannual date of registration of this phenophase. Researches concerning the grapes maturity put into evidence that it is closely correlated with the kinetics of maturation. (Vivas et al. 2003) have defined a model for the description of the dynamics of grapes maturation. It is a straight determined by the technological maturation index of grapes (sugar/acidity) and the sum of the temperature degree during the maturation period of the grapes. The value of the slope defines the kinetics of maturation, which can be very slow, slow, fast and very fast.

In this context, this study aimed to quantify the quality of the phenolic potential of grapes from Dealu Mare-Valea Calugareasca viticultural sortment and to correlate it with the operating 
component of the vine, such as earliness and the maturation kinetics of grapes.

\section{MATERIALS AND METHODS}

The study was conducted during 2012-2013 period, in the Appelation of Controlled Origin, Dealu Mare -Valea Călugărească, a wine producing area recognized mainly for the qualitative red wines. The varieties taken into study were: 'Burgund mare'(BM), 'Cabernet Sauvignon' (CS), 'Fetească neagră' (FN), 'Merlot' (ME) and 'Pinot noir' (PN). The climatic parameters characteristics for the maturation of the black grapes were defined by comparing the annual climatic parameters with the parameters of the multi-annual period of 1981 to 2011. The data from the climate database of IC-DVV Valea Calugareasca collected from the weather station belonging to the Institute, having the following coordinates: $44^{\circ} 59^{\prime} \mathrm{N}$ lat; $26^{\circ} 13^{\prime}$ E long; at the altitude of $210 \mathrm{~m}$. The precocity of varieties and the maturation kinetics of grapes were evaluated based on mathematical relation $\mathrm{Ij}=$ $\mathrm{f}(\mathrm{Cj})$ (Vivas et al., 2003), where Ij is the maturity corrected index and $\mathrm{Cj}$ the climatic index of the ripening period. The sloap of the straight $y=a x$ has defined the kinetiks of maturation on the 4 levels: very slow $(a<0,8)$, slow $(0,8<a<1,1)$, fast $(1,1$ $<\mathrm{a}<1,4)$ and very fast $(\mathrm{a}>1,4)$. The polyphenolic potential of the black grapes harvest was assesed by specific parameters: Total Polyphenol Index, Total anthocyanins, Anthocyanins extractibility (\%) and Contribute of grape seeds tannins as determined by Glories (1998), cited by Anneraud and Vinsonneau,(2009).

\section{RESULTS AND DISCUSSIONS Climate characterization during the maturation of grapes}

In the Appelation of Controlled Origin, Dealu Mare-Valea Calugareasca area, 2012 harvest, the climate of the ripening period (July-September) was very good in terms of air temperatures (mean values, minimum and maximum). Concerning 2013 harvest, the climate of the ripening period was good. They were dried years and rich in heatstroke.

The comparative analysis between annual and average values (representing the years 1981-2011) of temperature characterizing the maturation is shown in "Fig. 1".

\section{Veraison precocity}

During 2012 harvest, the period of veraison was 22 July-28 July, depending on the variety (Fig. 2). Concerning 2013 harvest, the veraison was conducted during 20 July and 26 July.

The precocity during 2013/2012 harvests varied depending of the variety, for Burgund mare, Cabernet Sauvignon and Merlot varieties was in average of 3 days, for Feteasca neagra 4 days and for Pinot noir 5 days (Tab. 1).

The grapes for winemaking were harvest during 10-17 September during 2012 and 18-23 September during 2013. Regarding 2012 harvest the grapes were collected with 7 - 8 days earlier in comparison with 2013 harvest (Fig. 3).

The period of time recorded between veraison and grapes harvesting was correlated with the harvest year and variety. Due to climate changes, and also to the variability of the harvest year, during 2013 compared to 2012 harvest, the period veraison-grapes harvesting was higher with 15 days for 'Feteasca neagra' variety, and with 8 days for 'Cabernet Sauvignon'.

\section{The kinetics of maturation of the Black Grapes for Winemaking}

The kinetics of maturation depended to the variety and was correlated with the regression coefficient and with «a» value (detemined for the sloap of the straight $y=a x)$. In Tab. 2 are presented considerations on the kinetics of maturation 2012/2013, as follows:

concerning 2012 harvest - was slow for 'Burgund mare' and ,Cabernet Sauvignon', to faster for ,Feteasca neagra', ,Merlot' and ,Pinot noir'

concerning 2013 harvest - was very slow regarding ,Burgund mare', ,Cabernet Sauvignon', ,Feteasca neagra' and ,Pinot noir', slow for ,Merlot'

The regression coefficient for 2012 harvest showed values between 0.9911 to 0.9929 from 'Merlot' and 'Pinot Noir'. Concerning 2013 harvest this coefficient ranged between 0,9916 at 'Pinot noir' and 0,9988 at 'Feteasca neagra'.

\section{Polyphenolic Potential of the Black Grapes for Winemaking}

The values of the analytical parameters which defined the phenolic potential of black grapes for winemaking, 2012 and 2013 harvests were collected in a base for the potential quantification presented in Tab. 3 . 


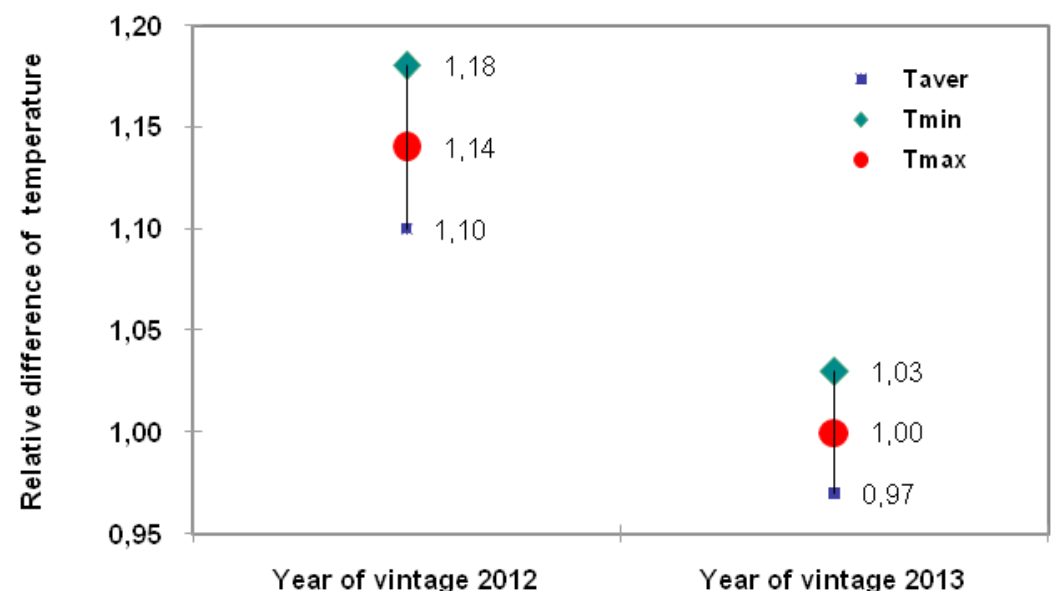

Fig. 1. Relative difference (annual/multiannual average) of temperature (mean, minimum and maximum) of grapes maturation during 2012 and 2013 harvests

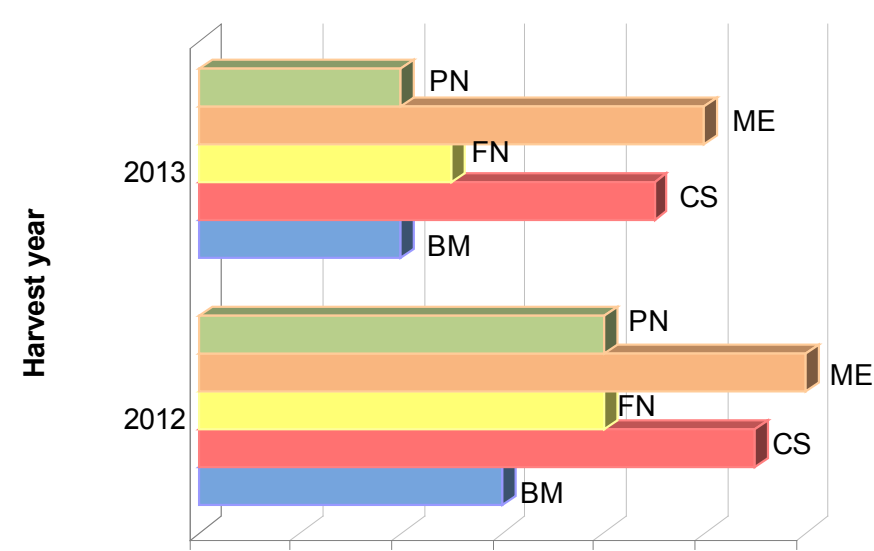

16-iul. 18-iul. 20-iul. 22-iul. 24-iul. 26-iul. 28-iul.

The calendar date

Fig. 2. Dates regarding the veraison of the black grapes for winemaking

Note: PN-'Pinot noir', ME-'Merlot', FN-'Feteasca neagra', CS-'Cabernet Sauvignon'; BM-'Burgund mare'

The analysis of the data put into evidence variations of parameters depending on the harvest year and variety. With the exception of Pinot noir, in case of all studied varieties and for the greatest part of the analytical parameters, total anthocyanins was assesed as very good to excellent for 2012 harvest and mediocre to good for 2013 harvest. The data's obtained should be correlated with literature data.

Referring to total anthocyanins extractability and to contribute of grape seeds tannins (UA), 2012 harvest was characterized as very good, while 2013 harvest mediocre.
Tab. 1. Comparative analysis regarding the veraison of the black grapes 2013/2012

\begin{tabular}{|c|c|c|c|}
\hline \multirow{2}{*}{ Variety } & \multicolumn{2}{|c|}{$\begin{array}{c}\text { Julian date } \\
\text { (number of days) }\end{array}$} & \multirow{2}{*}{$\begin{array}{c}\text { Differences } \\
\text { number of } \\
\text { days } \\
2013-2012\end{array}$} \\
\hline & 2012 & 2013 & \\
\hline 'Burgund mare' & 203 & 200 & -3 \\
\hline 'Cabernet Sauvignon' & 208 & 205 & -3 \\
\hline 'Feteasca neagra' & 205 & 201 & -4 \\
\hline 'Merlot' & 209 & 206 & -3 \\
\hline 'Pinot noir' & 205 & 200 & -5 \\
\hline Average & & & -3 \\
\hline
\end{tabular}




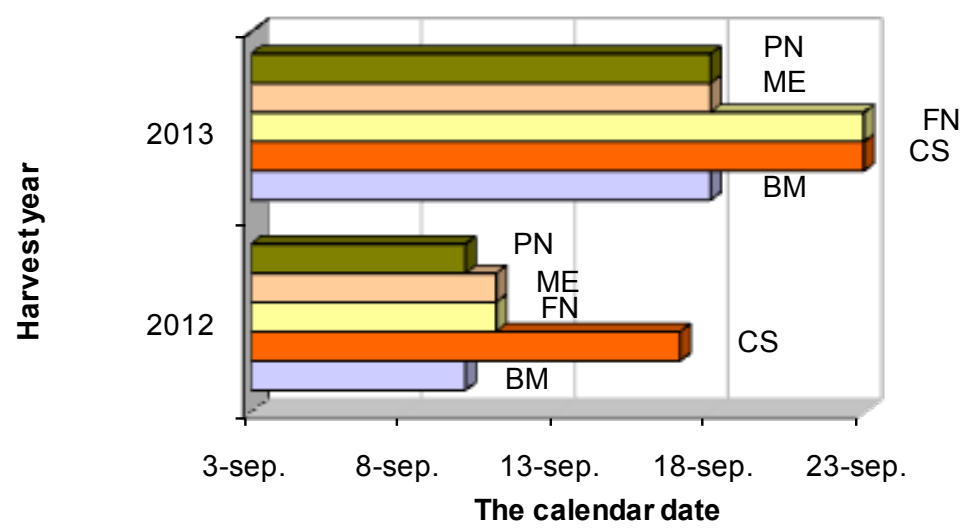

Fig. 3. Date of harvesting of black grapes for winemaking

Note: PN-'Pinot noir', ME-'Merlot', FN-'Feteasca neagra', CS-'Cabernet Sauvignon'; BM-'Burgund mare'

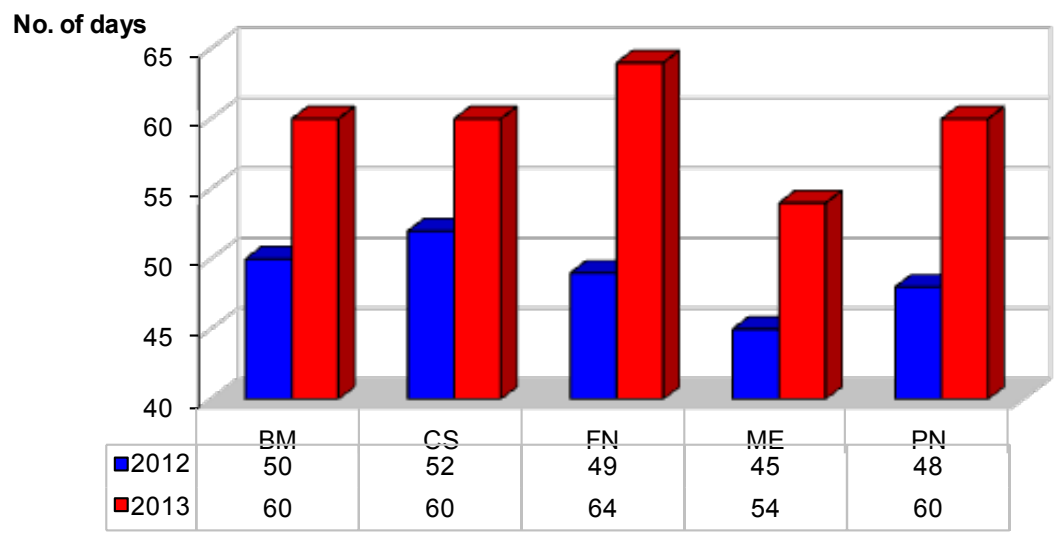

Fig. 4. Influence of the variety and the harvest year on the period of maturation

Note: PN-'Pinot noir', ME-'Merlot', FN-'Feteasca neagra', CS-'Cabernet Sauvignon'; BM-'Burgund mare'

Tab. 2. Harvest and variety specificity of the mathematical model for grapes maturation kinetics

\begin{tabular}{|c|c|c|c|}
\hline Variety & Regression coefficient & $\begin{array}{c}\text { Value of parameter «a» for } \\
\text { the regression } y=a x^{*}\end{array}$ & $\begin{array}{c}\text { Evaluation of grapes } \\
\text { maturation kinetiks } \\
\end{array}$ \\
\hline \multicolumn{4}{|c|}{2012 harvest } \\
\hline 'Burgund mare' & 0,9918 & 0,9032 & slow \\
\hline 'Cabernet Sauvignon' & 0,9925 & 1,0422 & slow \\
\hline 'Feteasca neagra' & 0,9913 & 1,2210 & fast \\
\hline 'Merlot' & 0,9911 & 1,1565 & fast \\
\hline 'Pinot noir' & 0,9929 & 1,2152 & fast \\
\hline \multicolumn{4}{|c|}{2013 harvest } \\
\hline 'Burgund mare' & 0,9955 & 0,7955 & very slow \\
\hline 'Cabernet Sauvignon' & 0,9919 & 0,7933 & very slow \\
\hline 'Feteasca neagra' & 0,9988 & 0,7880 & very slow \\
\hline 'Merlot' & 0,9985 & 0,9193 & slow \\
\hline 'Pinot noir' & 0,9916 & 0,7516 & very slow \\
\hline
\end{tabular}


Tab. 3. Base for the phenolic potential quantification of black grapes for winemaking

\begin{tabular}{|c|c|c|c|}
\hline \multirow{2}{*}{ Variety } & \multirow{2}{*}{ Analytical parameter } & \multicolumn{2}{|c|}{ Harvest year } \\
\hline & & 2012 & 2013 \\
\hline \multirow{4}{*}{ 'Burgund mare' } & Total Polyphenol Index (UA) & 47 & 41 \\
\hline & Total anthocyanins (mg/l) & 1132 & 1023 \\
\hline & Anthocyanins extractibility (\%) & 51 & 46 \\
\hline & Contribute of grape seeds tannins (UA) & 51 & 54 \\
\hline \multirow{4}{*}{ ‘Cabernet Sauvignon’ } & Total Polyphenol Index (UA) & 46 & 33 \\
\hline & Total anthocyanins $(\mathrm{mg} / \mathrm{l})$ & 1640 & 1531 \\
\hline & Anthocyanins extractibility (\%) & 46 & 43 \\
\hline & Contribute of grape seeds tannins (UA & 26 & 20 \\
\hline \multirow{4}{*}{ 'Feteasca neagra’ } & Total Polyphenol Index (UA) & 42 & 31 \\
\hline & Total anthocyanins $(\mathrm{mg} / \mathrm{l})$ & 1119 & 835 \\
\hline & Anthocyanins extractibility (\%) & 73 & 56 \\
\hline & Contribute of grape seeds tannins (UA) & 25 & 35 \\
\hline \multirow{4}{*}{ 'Merlot' } & Total Polyphenol Index (UA) & 46 & 36 \\
\hline & Total anthocyanins $(\mathrm{mg} / \mathrm{l})$ & 1281 & 1180 \\
\hline & Anthocyanins extractibility (\%) & 61 & 57 \\
\hline & Contribute of grape seeds tannins (UA) & 33 & 26 \\
\hline \multirow{4}{*}{ 'Pinot noir’ } & Total Polyphenol Index (UA) & 62 & 50 \\
\hline & Total anthocyanins $(\mathrm{mg} / \mathrm{l})$ & 480 & 376 \\
\hline & Anthocyanins extractibility (\%) & 74 & 67 \\
\hline & Contribute of grape seeds tannins (UA) & 77 & 80 \\
\hline
\end{tabular}

\section{CONCLUSION}

In the Appelation of Controlled Origin, Dealu Mare-Valea Calugareasca area, 2012-2013 harvests, the climate and the maturation of black grapes climatul have presented variety specificity. The average air temperature registered during the ripening of the grapes was higher with $2,6^{\circ} \mathrm{C}$ in 2012 in comparison with the same period in 2013. The veraison was recorded earlier with 3 days in 2013 and the harvesting later with 7 days compared to 2012 harvest. The kinetics of grapes maturation was very slow ing 2013 and rapid in 2012. The phenolic maturity of grapes at harvesting was very good for most of the features in 2012 and mediocre in 2013.

Acknowledgments. The study was developed within the framework the Sectorial Plan of the ADER 2020 PS 6.1.1./2011 entitled "Study and analysis for decision making wine sector in the implementation of CAP restrictions for the wine sector". 


\section{REFERENCES}

1. Anneraud C, Vinsonneau E (2009). Maturite technologique et maturite phenolique de raisins. Lettre actualites $41: 1$ 4.

2. Vivas N, Saint-Cricq de Gaulejac N, Yves G (1998) Maturation phénolique: definition et control
3. Vivas N, Nedjma M, Vivas de Gaulejac N, Nonier MF (2003). Critères d'adaptation et spécificité des méthodes de vinification et d'élevage des vins produits dans le bassin méditerranéen. Revue Française d'Oenologie.

4. http://www.enosens-coutras.fr/files/2015/07/ 4GLORIES.pdf 